Investigating the role of context in resolving discourse anaphoric relations: Does text genre variability play a part?

\author{
Eslami Rasekh, Abbas \\ University of Isfahan, Iran (abbasseslamirasekh@yahoo.com) \\ Tavakoli, Mansoor \\ University of Isfahan, Iran (mr.tavakoli14@gmail.com) \\ Ghadiri, Momene $\square$ \\ University of Isfahan, Iran (momene.ghadiri@gmail.com) \\ Zabihi, Reza \\ University of Isfahan, Iran (zabihi@ hotmail.com)
}

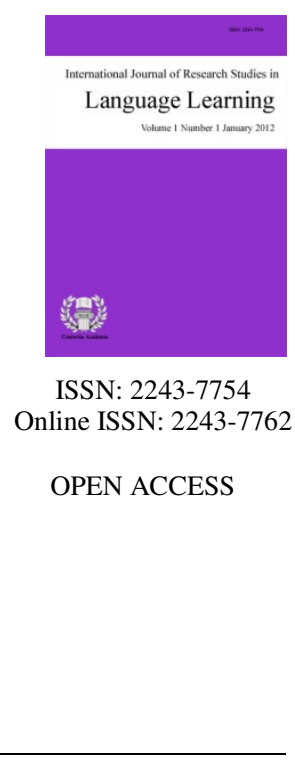

\title{
Abstract
}

This study was an attempt to investigate the effect of text genre variability on the identification of referents and the choice of various appropriate anaphoric expressions. A total number of 35 homogenous graduate and undergraduate female EFL learners were opted for the study. The data was mainly collected via email messages. Two pieces of English texts with blank NP slots, including an expository text and a narrative one, were sent for all the participants through an email message. The participants were provided ample time to study the texts carefully, identify the elliptic referents and choose appropriate anaphoric expressions. The results of qualitative analysis of the data indicated that: a) in some environments identification is difficult regardless of short referential distance; b) there may be NP slots in which the majority of participants identify the referent differently from the writer; c) the presence of grammatical constraint dictates full NP selection conformity; d) recency of prior mention strongly determines the selectional performance; e) NP slot may contain referents whose mentions are purely optional; f) a long referential distance, between five to 20 clauses intervening between the two subsequent mentions of a given referent, may not impact on the difficulty of identification of referent; g) there is no identical pattern of reference in all cases of NP selection. In all, concerning the identification of referents, the results revealed a significant difference between expository and narrative text genres $(p=.003<.05)$ though the difference between means were not high. With regards to the choice of anaphoric expressions, the results suggested significant difference between narrative and expository texts in terms of choice of NP of $(p=.003<0.05)$ and PRN $(p=.000<0.05)$.

Keywords: text genre variability; expository text; narrative text; identification of referents; choice of anaphoric expressions 


\section{Investigating the role of context in resolving discourse anaphoric relations: Does text genre variability play a part?}

\section{Introduction}

Of important issues in discourse studies of anaphora has been anaphor resolution (AR), or more simply, pronoun resolution, i.e., resolving references to mentioned or going to be mentioned terms. Put it in simple terms, AR is the procedure which one, as a reader, must go through to find out the mentioned entity (Mitkov, 2002). Eslami Rasekh (1997), while summarizing discourse studies of anaphor, refers to the problem of anaphor resolution as how to determine the linguistic referential device used, and the extra linguistic entity referred or the relationship between them (for further information, see Eslami Rasekh, 1997). Huang (2000) describes the problem of anaphoric distribution as follows:

"On the one hand, from the perspective of anaphoric production, what contributes to the speaker's choice of an appropriate anaphoric form; and on the other, from the vantage point of anaphoric resolution, what enables the addressee to identify the intended referent of that form at a given point in discourse?” (p. 302)

In view of this, the present study was aimed at examining the effect of text genre variability on the identification and the choice of various appropriate anaphoric expressions. Participants involved into two receptive and productive tasks. Indeed, they were supposed to comprehend two pieces of English expository and narrative texts, and subsequently, produce appropriate anaphoric expressions. In other words, this study was to answer the following questions:

1. Does text genre variability (narrative vs. expository) have any effect on the identification of the appropriate anaphoric expressions?

2. Does text genre variability (narrative vs. expository) have any effect on the choice of different anaphoric expressions?

\section{Theoretical Framework}

So far, three different approaches have been proposed concerning anaphora resolution in discourse. We try to explain those briefly in this part. We start by the one suggested earliest, namely, the context (givenness) approach, and move to the next two, i.e., distant approaches and focus approaches; of the three research approaches focus studies should be regarded as the latest and most developed one.

\subsection{The context approach to discourse anaphora}

According to this approach, a referential concept is enclosed within an episode boundary. In other words, by introducing the referent, it gets activated and is considered to remain active to the end of the given episode. By the episode being closed, the referent is not active any longer and a new topic initiates (Eslami Rasekh, 1997). Two notions are believed to be important in this approach: definiteness and givenness; we try to refer to them briefly below.

\subsubsection{Definiteness}

Initially, it was assumed that, generally, using definite descriptions, i.e., singular noun phrases accompanied with definite article, presumed an exclusive referent (cf. Laury, 2001).As Allen refers to it, speakers mostly tend to use a "definite NP" when they believe that the interlocutor can, "at least conceptually", recognize "the NP's 
denotatum" from "background knowledge", previously mentioned items, or from information brought to mind or induced from the given "context" (Allan 1986b, p.125).

\subsubsection{Discourse Givenness}

Givenness has been defined by Chafe (1976, p.30) as "knowledge which the speaker assumes to be in the consciousness of the addressee". Making distinction between given and new information, Chafe (1976) refers to previously activated information as given and considers new information as only being activated by the existing piece of text. Chafe further refers to "quasi-given" (1976, p. 34) as the information which is inferentially at hand. Moreover, three different bases of givenness have been recognized in Prince's (1981) work. Predictability/Recoverability originates from the fact that the speaker presupposes that the hearer can predict a particular entity may take place in a particular place in a sentence. Saliency arises from the fact that fact the speaker presupposes that the hearer, while perceiving the sound, may have some appropriate particular entities in his mind. Shared Knowledge arises from the fact that the speaker presupposes that the hearer is aware of, presume, or may deduce a particular entity, though the item may not essentially be in his thought (cf. Hempelmann et al., 2005).

\subsection{The Distant Approach to Discourse Anaphora}

Though context approach and givenness provides a distinction between given and new information, there are a number of referring expressions which cannot be categorized as given or new. Indeed, the degree of accessibility of the given referring expressions may be different. This led to the second research approach in anaphor resolution. In case of importance, the referent may be placed at the beginning of the sentence before comment; while, permanence of the entity, put it at the end of the sentence. In Givon's term, "a more predictable topic follows the comment, a less predictable topic precedes the comment" (Givon, 1989, p.225). Two concepts of topic continuity (TC) and accessibility theory (AC) are of importance in this approach.

\subsubsection{Topic Continuity (TC)}

Suggested by Givon $(1983,1985, \& 1990)$, the model states that anaphoric encoding in discourse is basically resolved by topic continuity. A number of factors have been proposed for measuring the continuity of topic in discourse including linear distance, which is the number of clause/sentence between the two mentions of a referent, referential interference, i.e., the number of interfering referents, and thematic information, namely, maintenance or change of the protagonist. To put it in simple terms, according to this model, when the linear distance is short, the numbers of referents at hand are low; thus, the protagonist has a more steady thematic status; and subsequently, it is more probable that the referent be encoded as a reduced anaphoric expression (for further information, see Huang, 2000). However, topic continuity cannot give an explanation for atypical referential choices across episode boundaries (cf. Eslami Rasekh, 1997). Moreover, the model may account for anaphor resolution in narrative genre well; yet, other genres may contain different structural features (Allan, 1987b).

\subsubsection{Accessibility Theory (AT)}

According to this theory, the choice of referring expression arises from the fact that to what extent the referent is believed to be in the interlocutor's mind. If the referent is regarded as highly accessible in his mind, the less explicit referring expression, including pronoun, may be selected. However, if it is supposed not to be represented in interlocutor's mental image, more explicit referring expressions, including proper nouns, may be chosen in order to make the process of comprehension easier (cf. Ariel, 1990; Chafe, 1994; Givón, 1983; Prince, 1981). Thus, what matters in the choice of appropriate anaphoric expressions is the presumption regarding the interlocutor's present center of attention (Fukumura \& van Gompel, 2009). Arnold \& Tanenhaus (2007) put forward that the highly accessible entities, which can be mentioned with the use of pronouns, are of less prominence in comparison to those which are less focused and pronoun substitution is less probable for them. 


\subsection{The Focus Approach to Discourse Anaphora}

The last research approach discussed in this study, which is the latest one as well, is focus approach. What this approach advocates is that the choice of anaphoric expression is the result of episodic boundary in discourse and not the referential distance. As Tomlin (1987) puts forward, there are many instances which cannot be accounted for by distance approach and no explanation has been provided so far. Here, we refer to centering and hierarchical discourse structure, which is central in focus studies.

\subsubsection{Centering}

This model put emphasis on the cognitive processes of mind, including activation and attention, in the choice of appropriate anaphoric expressions. Activation and attention, although closely related, are two separate cognitive phenomena. In fact, activation of a referent arises from centering attention on that referent just mentioned (e.g. Chafe, 1994; Kibrik, 1996). More simply, the model claims that when the referent is not activated in the mind of the hearer, full NPs are likely to be chosen; while, if the referent is supposed to be available in the mental representation of both speaker and hearer, pronouns, or even zero anaphors, more probable (cf. Tomlin, 1987; Tomlin and Pu, 1991; Gundel et al., 1993; Kibrik, 1996).

\subsubsection{Hierarchical Discourse Structure}

According to this model, what matters in the choice of anaphoric expressions is the hierarchical structure of discourse. Hence, if the referent is to be mentioned for the first time, a full NP may be selected; however, if the referent is to be mentioned again, a reduced anaphoric expression would be chosen within that discourse structure (cf. Huang, 2000). One the chief studies of hierarchical structure in discourse has been done by Fox (1987). Fox comes to the point that discourse organization and choice of anaphoric expressions are interrelated. According to her, there are cases in which the hierarchical structure of discourse determines the choice of anaphoric expressions, referred to as "context-determine-use" and there are cases in which a particular anaphoric expression forces a particular structure of discourse, referred to as "use-accomplishes-context". Thus, hierarchical structure of discourse, in her terms, is central in determining appropriate anaphoric expressions.

\section{Research methodology}

\subsection{Participants}

A total number of thirty-five advanced Iranian graduate and undergraduate students of English, studying or studied English at the University of Isfahan, Faculty of Foreign Languages, Department of English participated in this study. Their age ranged between 21 and 28 . The sample consisted mostly of senior student.

\subsection{Instrumentation}

Two pieces of English texts, each with 35 NP slots, including an expository text (see Appendix 1) and a narrative one (see Appendix 2) were used in this study. Only the first mention of the topical participants was given; all the subsequent references were indicated by empty NP slots left for the participants to spell out.

\subsubsection{Expository Text}

Concerning the expository text, the readability of the text came out to be 28 , meaning very difficult. Thus five instructors, who taught reading courses both at higher academic levels, were invited to judge the level of difficulty of the text. Three instructors considered it difficult and appropriate for advanced students; one consider it difficult, however, suitable for upper intermediate students; and one evaluated it fairy difficult and appropriate for advanced students. In order to make sure about the level of difficulty of the selected text, in a pilot study, the text was given to both advanced and upper intermediate students. The indexes of item facility and item difficulty of each slot were calculated; furthermore, participants' own evaluations of the level of difficulty of the text were 
checked out. Results revealed that the text is mostly appropriate for advanced students rather than upper intermediate ones. In all, based on the Flesch-Kincaid readability formula, five instructors' ideas, and pilot study, the text was selected for advanced students. The text selected for this study was a piece of news titled Holder defends terror trials in civilian courts revealed by Associated Press, June 16, 2011. The text was written by journalist Nedra Pickler. The news story was about Attorney General Eric Holder who were fought over the prosecution of terrorism suspects in civilian court and urged by the top-ranking Senate Republican Mitch McConnell to send two Iraqis Waad Ramadan Alwan and Mohanad Shareef Hammadi to Guantanamo Bay rather than try them in Kentucky.

\subsubsection{Narrative Text}

The story selected for this study was taken from the book The Chamber by John Grisham, retold by Sue Harmes and edited by Andy Hopkins and Jocelyn Potter. The book has been evaluated by Penguin Readers as appropriate for advanced students. The Chamber consisted of fourteen chapters. The story selected for this study was opted from the first chapter, A Delicate Exercise. The story was about the Mississippi Klan leader Dogan who together with Sam Cayhall and Rollie Wedge planned to assassinate the Jewish lawyer Martin B. Kramer.

\subsection{Data Collection Procedures}

The data of this study was mainly collected via email messages. Ten days before the main study, a pilot study using participants with a background similar to the participants of the main study was conducted in an effort to verify the appropriateness of all the tests designed for the study. Based on the result of the pilot study, internal consistencies (Cranach's alphas) were calculated for both expository and narrative text genres; though cloze tests are not potentially reliable due to their interrelatedness of their items, internal reliability estimates were respectable, ranging from .68 for the thirty five slots on the expository text genre to .73 for the thirty five slots on the narrative text genre. Next, two English text genres were sent for all the participants through email message. The participants were provided ample time to study the texts carefully, identify the ellipted referents and choose appropriate anaphoric expressions.

\subsection{Data Analysis and Scoring}

Appropriate descriptive statistical procedures such as frequencies, percentages and means were used to interpret the results of the study quantitatively. In addition, a paired t-test was run to determine the significant difference between students' performance in both identification of referents and choice of referring expressions within the expository text genre vs. narrative one. Concerning scoring, In order to score the cloze tests, the acceptable scoring method was used. That is, any response which is acceptable in the context obtained a score and any incorrect response was not given any.

\section{Findings}

\subsection{Students' Performance on Identification of the Referents}

Following are the results of the analysis of expository text concerning identification of referents. The analysis of data will be presented quantitatively slot by slot. 
Table 1

Correct Identification of Referents (\%), Expository text

\begin{tabular}{|c|c|c|c|}
\hline Slots & Frequency & Percent & Valid Percent \\
\hline Slot 1 & 24 & 68.57 & 68.57 \\
\hline Slot 2 & 15 & 42.85 & 42.85 \\
\hline Slot 3 & 24 & 68.57 & 68.57 \\
\hline Slot 4 & 29 & 82.9 & 82.9 \\
\hline Slot 5 & 29 & 82.9 & 82.9 \\
\hline Slot 6 & 19 & 54.28 & 54.28 \\
\hline Slot 7 & 12 & 34.38 & 34.38 \\
\hline Slot 8 & 33 & 94.28 & 94.28 \\
\hline Slot 9 & 23 & 65.71 & 65.71 \\
\hline Slot 10 & 20 & 57.14 & 57.14 \\
\hline Slot 11 & 23 & 65.71 & 65.71 \\
\hline Slot 12 & 30 & 85.71 & 85.71 \\
\hline Slot 13 & 17 & 48.57 & 48.57 \\
\hline Slot 14 & 19 & 54.28 & 54.28 \\
\hline Slot 15 & 12 & 34.28 & 34.28 \\
\hline Slot 16 & 15 & 42.85 & 42.85 \\
\hline Slot 17 & 22 & 62.85 & 62.85 \\
\hline Slot 18 & 25 & 71.42 & 71.42 \\
\hline Slot 19 & 20 & 57.14 & 57.14 \\
\hline Slot 20 & 16 & 45.71 & 45.71 \\
\hline Slot 21 & 12 & 34.28 & 34.28 \\
\hline Slot 22 & 13 & 37.14 & 37.14 \\
\hline Slot 23 & 17 & 48.57 & 48.57 \\
\hline Slot 24 & 16 & 45.71 & 45.71 \\
\hline Slot 25 & 17 & 48.57 & 48.57 \\
\hline Slot 26 & 35 & 100.0 & 100.0 \\
\hline Slot 27 & 35 & 100.0 & 100.0 \\
\hline Slot 28 & 35 & 100.0 & 100.0 \\
\hline Slot 29 & 35 & 100.0 & 100.0 \\
\hline Slot 30 & 35 & 100.0 & 100.0 \\
\hline Slot 31 & 13 & 37.14 & 37.14 \\
\hline Slot 32 & 13 & 37.14 & 37.14 \\
\hline Slot 33 & 13 & 37.14 & 37.14 \\
\hline Slot 34 & 35 & 100.0 & 100.0 \\
\hline Slot 35 & 31 & 88.57 & 88.57 \\
\hline
\end{tabular}

Following are the results of the analysis of narrative text concerning identification of referents. The analysis of data will be presented quantitatively slot by slot.

In order to ascertain whether there is a significant difference in identification of referents between the two text genres, the paired sample t-test was performed. The results suggested significant difference between narrative and expository texts in terms of identification of referents $(p=.003<0.05)$, though the difference between means were not high; students could identify $81.06 \%$ of referents in narrative text genres and $63.59 \%$ of referents in expository one (see tables 3 and 4 ). 
Table 2

Correct Identification of Referents (\%), Narrative text

\begin{tabular}{|c|c|c|c|}
\hline Slots & Frequency & Percent & Valid Percent \\
\hline Slot 1 & 34 & 97.14 & 97.14 \\
\hline Slot 2 & 33 & 94.28 & 94.28 \\
\hline Slot 3 & 33 & 94.28 & 94.28 \\
\hline Slot 4 & 33 & 94.28 & 94.28 \\
\hline Slot 5 & 33 & 94.28 & 94.28 \\
\hline Slot 6 & 33 & 94.28 & 94.28 \\
\hline Slot 7 & 34 & 97.14 & 97.14 \\
\hline Slot 8 & 32 & 91.42 & 91.42 \\
\hline Slot 9 & 32 & 91.42 & 91.42 \\
\hline Slot 10 & 16 & 45.71 & 45.71 \\
\hline Slot 11 & 29 & 82.85 & 82.85 \\
\hline Slot 12 & 29 & 82.85 & 82.85 \\
\hline Slot 13 & 35 & 100.0 & 100.0 \\
\hline Slot 14 & 35 & 100.0 & 100.0 \\
\hline Slot 15 & 28 & 80.0 & 80.0 \\
\hline Slot 16 & 35 & 100.0 & 100.0 \\
\hline Slot 17 & 35 & 100.0 & 100.0 \\
\hline Slot 18 & 28 & 80.0 & 80.0 \\
\hline Slot 19 & 35 & 100.0 & 100.0 \\
\hline Slot 20 & 15 & 42.85 & 42.85 \\
\hline Slot 21 & 15 & 42.85 & 42.85 \\
\hline Slot 22 & 33 & 94.28 & 94.28 \\
\hline Slot 23 & 35 & 100.0 & 100.0 \\
\hline Slot 24 & 30 & 85.7 & 85.7 \\
\hline Slot 25 & 14 & 40.0 & 40.0 \\
\hline Slot 26 & 30 & 85.7 & 85.7 \\
\hline Slot 27 & 35 & 100.0 & 100.0 \\
\hline Slot 28 & 14 & 40.0 & 40.0 \\
\hline Slot 29 & 35 & 100.0 & 100.0 \\
\hline Slot 30 & 30 & 85.7 & 85.7 \\
\hline Slot 31 & 13 & 37.14 & 37.14 \\
\hline Slot 32 & 35 & 100.0 & 100.0 \\
\hline Slot 33 & 14 & 40.0 & 40.0 \\
\hline Slot 34 & 12 & 34.28 & 34.28 \\
\hline Slot 35 & 31 & 88.57 & 88.57 \\
\hline
\end{tabular}

Table 3

Comparison of Students' Performances in Identification of Referents: Narrative vs. Expository Text Genre

\begin{tabular}{cccccc}
\hline & & Mean & N & Std. Deviation & Std. Error Mean \\
\cline { 2 - 6 } Pair 1 & Expository & 22.2571 & 35 & 8.25456 & 1.39528 \\
& Narrative & 28.3714 & 35 & 8.16047 & 1.37937 \\
\hline
\end{tabular}

\section{Table 4}

Comparison of Students' Performances in Identification of Referents: Narrative vs. Expository Text Genre

Pair 1

Expository-Narrative

\begin{tabular}{cccccc}
\multicolumn{2}{c}{ Paired Difference } & & $\mathrm{T}$ & $\mathrm{df}$ & $\mathrm{Sig}$ (2-tailed) \\
\cline { 1 - 2 } Mean & Std. deviation & & & \\
\hline-6.11429 & 11.14021 & -3.247 & 34 & .003 \\
\hline
\end{tabular}


Eslami, R. A., Tavakoli, M., Ghadiri, M., \& Zabihi, R.

\subsection{Students' Performance in the Choice of the Referring Expressions}

In analysis of the choice of the referring expressions, the percent of the use of full NP in comparison to the use of pronoun investigated quantitatively. The term full NP refers to any definite referent marked by a non-pronominal expression, whether or not the expression in question is a first name, a last name, a noun without any attachment, or a noun with a determiner, a title, a description, etc. In analysis of the choice anaphoric expressions, first the original writer's choice of expressions will be presented, then participants' choices will be discussed.

\section{Table 5}

Writer's Choice of Referring Expressions, Expository Text

\begin{tabular}{|c|c|c|}
\hline Slots & Referring Expressions & Category \\
\hline Slot 1 & Holder & $\mathrm{NP}$ \\
\hline Slot 2 & civilian courts & NP \\
\hline Slot 3 & Holder & NP \\
\hline Slot 4 & Holder & NP \\
\hline Slot 5 & his & PRN \\
\hline Slot 6 & McConnell & NP \\
\hline Slot 7 & Holder's & NP \\
\hline Slot 8 & terrorism suspects & NP \\
\hline Slot 9 & he & PRN \\
\hline Slot 10 & civilian courts & NP \\
\hline Slot 11 & Holder & NP \\
\hline Slot 12 & terrorists & NP \\
\hline Slot 13 & Holder & NP \\
\hline Slot 14 & terrorism suspects & NP \\
\hline Slot 15 & military commission & NP \\
\hline Slot 16 & McConnell & NP \\
\hline Slot 17 & Holder's & NP \\
\hline Slot 18 & terrorists & NP \\
\hline Slot 19 & McConnell & NP \\
\hline Slot 20 & Holder & NP \\
\hline Slot 21 & His & PRN \\
\hline Slot 22 & civilian courts & NP \\
\hline Slot 23 & Holder & NP \\
\hline Slot 24 & terror suspects & NP \\
\hline Slot 25 & civilian courts & NP \\
\hline Slot 26 & Alwan & NP \\
\hline Slot 27 & Hammadi & NP \\
\hline Slot 28 & the men & NP \\
\hline Slot 29 & they & PRN \\
\hline Slot 30 & The two & NP \\
\hline Slot 31 & weapon & NP \\
\hline Slot 32 & money & NP \\
\hline Slot 33 & Alwan and Hammadi & NP \\
\hline Slot 34 & The FBI & NP \\
\hline Slot 35 & his & PRN \\
\hline
\end{tabular}

Table 6

Writer's Choice of Referring Expressions (\%), Expository Text

\begin{tabular}{ccc}
\hline & NP $(\%)$ & PRN $(\%)$ \\
\hline Expository text & 85.71 & 14.28 \\
\hline
\end{tabular}

Participants' choices of referring expressions in expository text genre are as follows: 
Investigating the role of context in resolving discourse anaphoric relations

Table 7

Participants' Choice of Referring Expressions (\%), Expository Text

\begin{tabular}{|c|c|c|c|c|c|}
\hline Slots & $\mathrm{NP}(\%)$ & PRN (\%) & & istakes & \\
\hline & & & NP $(\%)$ & PRN (\%) & Missing (\%) \\
\hline Slot 1 & 68.57 & 0 & 8.571 & 22.85 & 0 \\
\hline Slot 2 & 42.85 & 0 & 25.71 & 22.85 & 8.57 \\
\hline Slot 3 & 31.42 & 37.14 & 2.85 & 22.85 & 5.714 \\
\hline Slot 4 & 82.85 & 0 & 5.71 & 11.42 & 0 \\
\hline Slot 5 & 0 & 82.85 & 5.71 & 11.42 & 0 \\
\hline Slot 6 & 54.28 & 0 & 0 & 45.71 & 0 \\
\hline Slot 7 & 34.28 & 0 & 0 & 14.28 & 51.42 \\
\hline Slot 8 & 94.28 & 0 & 0 & 0 & 5.71 \\
\hline Slot 9 & 31.42 & 34.28 & 28.57 & 0 & 5.71 \\
\hline Slot 10 & 57.14 & 0 & 28.57 & 0 & 14.28 \\
\hline Slot 11 & 65.714 & 0 & 17.14 & 17.14 & 0 \\
\hline Slot 12 & 85.714 & 0 & 14.28 & 0 & 0 \\
\hline Slot 13 & 40 & 8.57 & 0 & 0 & 51.42 \\
\hline Slot 14 & 54.285 & 0 & 40 & 0 & 5.714 \\
\hline Slot 15 & 34.28 & 0 & 37.14 & 0 & 28.57 \\
\hline Slot 16 & 42.85 & 0 & 31.42 & 25.71 & 0 \\
\hline Slot 17 & 62.85 & 0 & 20 & 17.14 & 0 \\
\hline Slot 18 & 71.42 & 0 & 28.57 & 0 & 0 \\
\hline Slot 19 & 57.14 & 0 & 31.42 & 11.42 & 0 \\
\hline Slot 20 & 45.71 & 0 & 40 & 14.28 & 0 \\
\hline Slot 21 & 0 & 34.28 & 34.28 & 31.42 & 0 \\
\hline Slot 22 & 37.14 & 0 & 28.57 & 25.71 & 8.57 \\
\hline Slot 23 & 48.57 & 0 & 28.57 & 22.85 & 0 \\
\hline Slot 24 & 45.71 & 0 & 22.85 & 28.57 & 2.85 \\
\hline Slot 25 & 48.57 & 0 & 22.85 & 28.57 & 0 \\
\hline Slot 26 & 100 & 0 & 0 & 0 & 0 \\
\hline Slot 27 & 100 & 0 & 0 & 0 & 0 \\
\hline Slot 28 & 100 & 0 & 0 & 0 & 0 \\
\hline Slot 29 & 8.57 & 91.42 & 0 & 0 & 0 \\
\hline Slot 30 & 8.57 & 91.42 & 0 & 0 & 0 \\
\hline Slot 31 & 37.14 & 0 & 34.28 & 0 & 28.57 \\
\hline Slot 32 & 37.14 & 0 & 34.28 & 0 & 28.57 \\
\hline Slot 33 & 20 & 17.14 & 11.42 & 0 & 51.42 \\
\hline Slot 34 & 65.71 & 34.28 & 0 & 0 & 0 \\
\hline Slot 35 & 45.71 & 42.85 & 0 & 11.42 & 0 \\
\hline
\end{tabular}

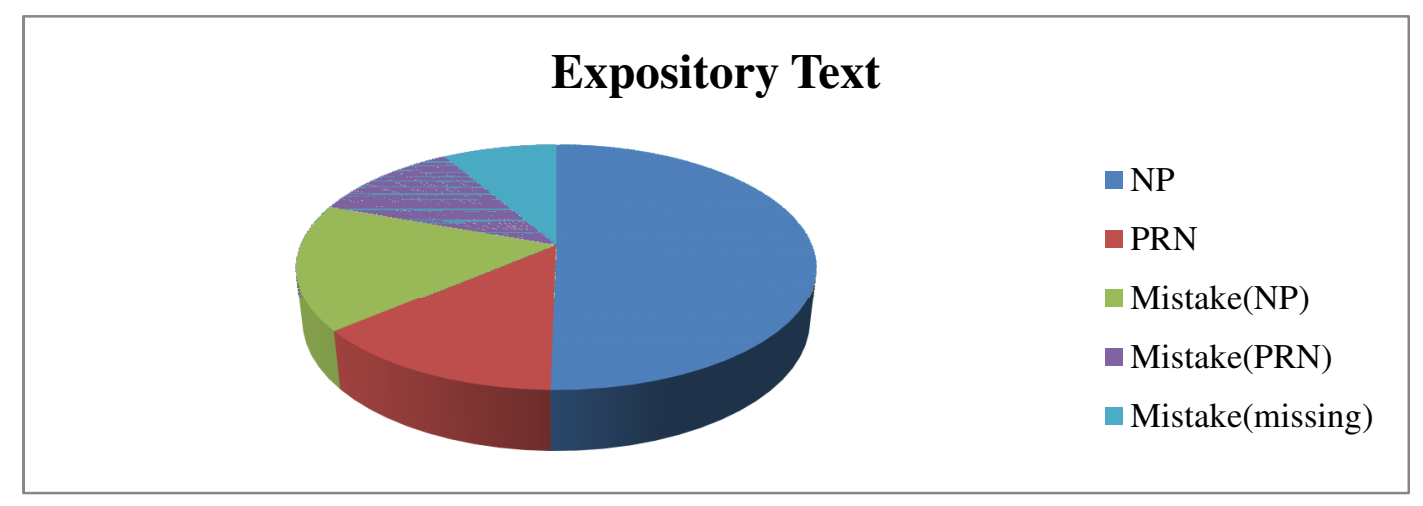

Figure 1. Choice of Referring Expressions: English Expository Text 
Eslami, R. A., Tavakoli, M., Ghadiri, M., \& Zabihi, R.

The original writer's choice of expressions in narrative text genre is as follows:

\section{Table 8}

Writer's Choice of Referring Expressions, Narrative Text

\begin{tabular}{|c|c|c|}
\hline Slots & Referring Expressions & Category \\
\hline Slot 1 & Cayhall & NP \\
\hline Slot 2 & Kramer & NP \\
\hline Slot 3 & $\mathrm{He}$ & PRN \\
\hline Slot 4 & $\mathrm{He}$ & PRN \\
\hline Slot 5 & $\mathrm{He}$ & PRN \\
\hline Slot 6 & $\mathrm{He}$ & PRN \\
\hline Slot 7 & Sam Cayhall & NP \\
\hline Slot 8 & Dogan & NP \\
\hline Slot 9 & the Cayhall & NP \\
\hline Slot 10 & Klan & NP \\
\hline Slot 11 & $\mathrm{He}$ & PRN \\
\hline Slot 12 & $\mathrm{He}$ & PRN \\
\hline Slot 13 & Cayhall & NP \\
\hline Slot 14 & $\mathrm{He}$ & PRN \\
\hline Slot 15 & It & PRN \\
\hline Slot 16 & $\mathrm{He}$ & PRN \\
\hline Slot 17 & $\mathrm{He}$ & PRN \\
\hline Slot 18 & Sam Cayhall & NP \\
\hline Slot 19 & His son & NP \\
\hline Slot 20 & Cayhall & NP \\
\hline Slot 21 & the young man & NP \\
\hline Slot 22 & They & PRN \\
\hline Slot 23 & They & PRN \\
\hline Slot 24 & the two men & NP \\
\hline Slot 25 & Cayhall & NP \\
\hline Slot 26 & They & PRN \\
\hline Slot 27 & Kramer's & NP \\
\hline Slot 28 & Cayhall & NP \\
\hline Slot 29 & Kramer's & NP \\
\hline Slot 30 & The men & NP \\
\hline Slot 31 & The box & NP \\
\hline Slot 32 & They & PRN \\
\hline Slot 33 & Rollie & NP \\
\hline Slot 34 & The closet & NP \\
\hline Slot 35 & $\mathrm{He}$ & PRN \\
\hline
\end{tabular}

Table 9

Writer's Choice of Referring Expressions (\%), Narrative Text

\begin{tabular}{lll}
\hline & NP $(\%)$ & PRN $(\%)$ \\
\hline Narrative Text & 42.85 & $57.14 \%$ \\
\hline
\end{tabular}

Participants' choices of referring expressions in narrative text genre are as follows: 
Table 10

Participants' Choice of Referring Expressions (\%), Narrative Text

\begin{tabular}{|c|c|c|c|c|c|}
\hline \multirow[t]{2}{*}{ Slots } & \multirow[t]{2}{*}{$\mathrm{NP}(\%)$} & \multirow[t]{2}{*}{ PRN (\%) } & \multicolumn{2}{|c|}{ Mistakes } & \multirow[b]{2}{*}{ Missing (\%) } \\
\hline & & & NP $(\%)$ & PRN (\%) & \\
\hline Slot 1 & 97.14 & 0 & 2.85 & 0 & 0 \\
\hline Slot 2 & 94.28 & 0 & 2.85 & 2.85 & 0 \\
\hline Slot 3 & 0 & 94.28 & 5.71 & 0 & 0 \\
\hline Slot 4 & 25.71 & 68.57 & 5.71 & 0 & 0 \\
\hline Slot 5 & 37.14 & 57.14 & 5.71 & 0 & 0 \\
\hline Slot 6 & 17.14 & 77.14 & 5.71 & 0 & 0 \\
\hline Slot 7 & 97.14 & 0 & 2.85 & 0 & 0 \\
\hline Slot 8 & 91.42 & 0 & 0 & 8.57 & 0 \\
\hline Slot 9 & 42.85 & 48.57 & 8.57 & 0 & 0 \\
\hline Slot 10 & 45.71 & 0 & 54.28 & 0 & 0 \\
\hline Slot 11 & 22.85 & 60 & 11.42 & 5.71 & 0 \\
\hline Slot 12 & 22.85 & 60 & 11.42 & 5.71 & 0 \\
\hline Slot 13 & 100 & 0 & 0 & 0 & 0 \\
\hline Slot 14 & 0 & 100 & 0 & 0 & 0 \\
\hline Slot 15 & 5.71 & 74.28 & 0 & 0 & 20 \\
\hline Slot 16 & 0 & 100 & 0 & 0 & 0 \\
\hline Slot 17 & 0 & 100 & 0 & 0 & 0 \\
\hline Slot 18 & 80 & 0 & 20 & 0 & 0 \\
\hline Slot 19 & 0 & 100 & 0 & 0 & 0 \\
\hline Slot 20 & 11.42 & 31.42 & 25.71 & 31.42 & 0 \\
\hline Slot 21 & 11.42 & 31.42 & 20 & 37.14 & 0 \\
\hline Slot 22 & 0 & 94.28 & 5.714 & 0 & 0 \\
\hline Slot 23 & 0 & 100 & 0 & 0 & 0 \\
\hline Slot 24 & 51.42 & 34.28 & 8.57 & 5.71 & 0 \\
\hline Slot 25 & 40 & 0 & 40 & 20 & 0 \\
\hline Slot 26 & 17.14 & 68.57 & 0 & 14.28 & 0 \\
\hline Slot 27 & 100 & 0 & 0 & 0 & 0 \\
\hline Slot 28 & 40 & 0 & 40 & 20 & 0 \\
\hline Slot 29 & 28.57 & 71.42 & 0 & 0 & 0 \\
\hline Slot 30 & 17.14 & 68.57 & 8.57 & 5.714 & 0 \\
\hline Slot 31 & 37.14 & 0 & 48.57 & 14.28 & 0 \\
\hline Slot 32 & 0 & 100 & 0 & 0 & 0 \\
\hline Slot 33 & 40 & 0 & 40 & 20 & 0 \\
\hline Slot 34 & 34.28 & 0 & 42.85 & 22.85 & 0 \\
\hline Slot 35 & 17.14 & 71.42 & 11.42 & 0 & 0 \\
\hline
\end{tabular}

\section{Table 11}

Participants' Choice of Referring Expressions (\%), Narrative Text

\begin{tabular}{lll|l|l|l}
\hline \multirow{2}{*}{ Slots } & NP (\%) & \multicolumn{3}{c}{ PRN (\%) } & \multicolumn{3}{c}{ Mistakes } \\
\cline { 4 - 6 } & & NP (\%) & PRN (\%) & Missing (\%) \\
\hline Slot $1-35$ & 35.01 & 46.03 & 12.24 & 6.12 & 0.57 \\
\hline
\end{tabular}

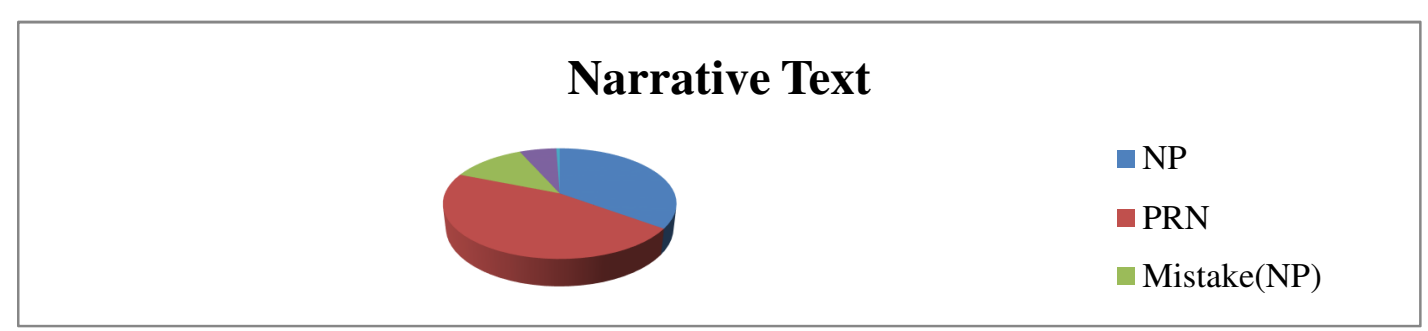

Figure 2. Choice of Referring Expressions: English Expository Text 
Eslami, R. A., Tavakoli, M., Ghadiri, M., \& Zabihi, R.

In order to ascertain whether there is a significant difference in the choice of referring expressions between the two text genres, the paired sample t-test was performed. The results suggested significant difference between narrative and expository texts in terms of choice of NP of $(\mathrm{p}=.003<0.05)$ and PRN $(\mathrm{p}=.000<0.05)$ (see tables $8,9,10, \& 11)$.

\section{Table 12}

Comparison of Students' Performances in the Choice of NP Referring Expressions: English Expository Text vs.

English Narrative Text

\begin{tabular}{llllll}
\hline & & Mean & $\mathrm{N}$ & Std. Deviation & Std. Error Mean \\
\hline Pair 1 & Expository & .5714 & 35 & .50210 & .08487 \\
& Narrative & .3429 & 35 & .48159 & .08140 \\
\hline
\end{tabular}

\section{Table 13}

Comparison of Students' Performances in the Choice of NP Referring Expressions: English Expository Text vs.

English Narrative Text

\begin{tabular}{llllll}
\hline \multirow{2}{*}{$\begin{array}{l}\text { Pair } 1 \\
\text { Expository-Narrative }\end{array}$} & \multicolumn{2}{c}{ Paired Difference } & \multirow{2}{*}{$\mathrm{T}$} & $\mathrm{d}$ df & \multirow{2}{*}{ Sig(2-tailed) } \\
\cline { 2 - 5 } & Mean & Std. deviation & & & \\
\cline { 2 - 6 } & .22857 & .42604 & 3.174 & 34 & .003 \\
\hline
\end{tabular}

\section{Table 14}

Comparison of Students' Performances in the Choice of PRN Referring Expressions: English Expository Text vs.

English Narrative Text

\begin{tabular}{llllll}
\hline & Mean & $\mathrm{N}$ & Std. Deviation & Std. Error Mean \\
\hline Pair 1 & Expository & .1143 & 35 & .32280 & .05456 \\
& Narrative & .4571 & 35 & .50543 & .08543 \\
\hline
\end{tabular}

\section{Table 15}

Comparison of Students' Performances in the Choice of PRN Referring Expressions: English Expository Text vs. English Narrative Text

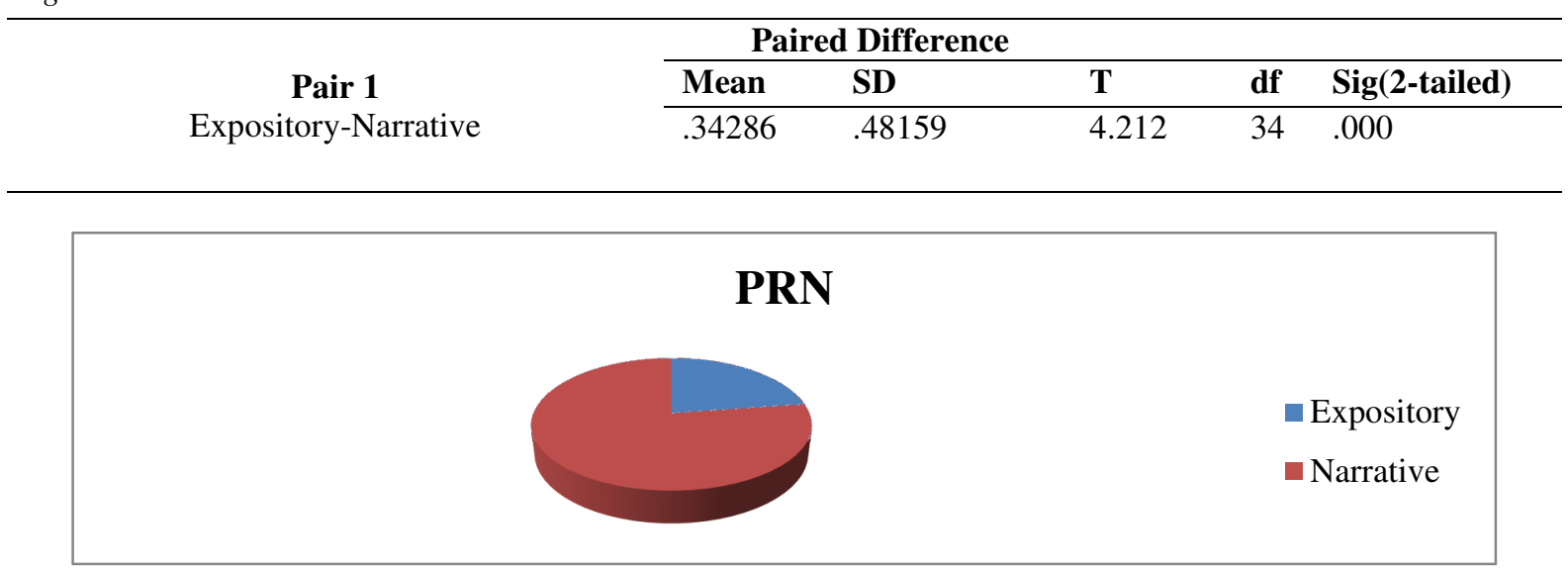

Figure 3. Choice of Referring Expressions: English Expository Text vs. English Narrative Text 


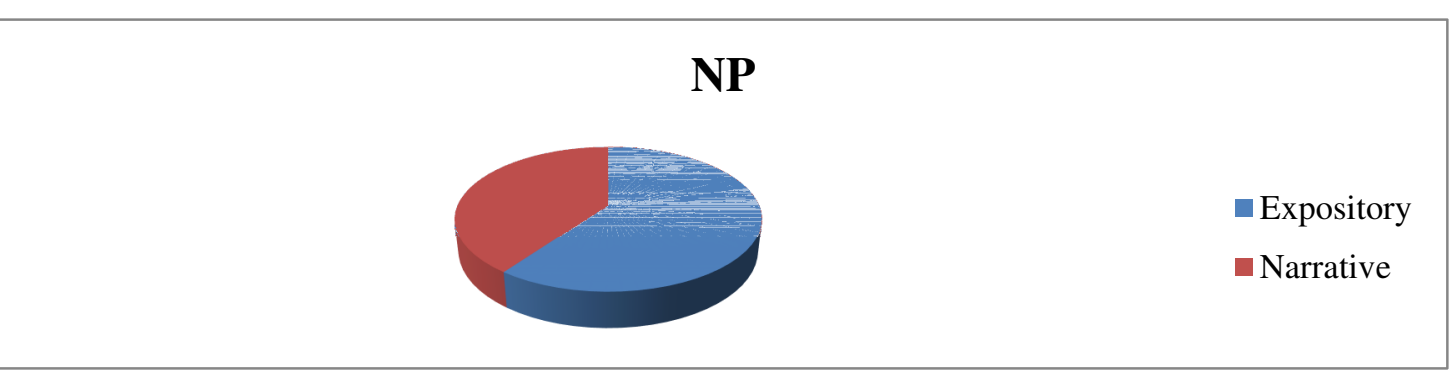

Figure 4. Choice of Referring Expressions: English Expository Text vs. English Narrative Text

\section{Discussion}

As narrative texts deal with events that "occur through time" and are "related through a causal or thematic chain" (cf. Brewer's, 1980, p. 223), or share life experiences which is familiar to the readers and the language close to spoken one (Bruner, 1986; Rubin, 1995; Tonjes, Wolpow, \& Zintz, 1999), most readers possess the knowledge necessary to understand it, though the text may contain unfamiliar information (Cot'e et al., 1998; Nelson, 1996). Furthermore, the terms which are used in narrative text genre is of high-frequency word and the structure of the text is simple. Therefore, not much load is put on the working memory and comprehension, hence, is easier (Williams et al., 2004; Cain, 1996; Cot'e et al., 1998). Therefore, identification of referents is effortless and participants tend to use more pronominal expressions than nominal ones.

In contrast to narrative texts, the expository texts are to tell readers new information. Therefore, it is not surprising to find concepts which are unfamiliar to most readers. Moreover, due to the structural complexity of the text as well as greater information density, an additional load is put on one's mental capacity and subsequently working memory is to process more demanding pieces of information (McNamara, Graesser, \& Louwerse, in press). Hence, identification of referents is not easy, in comparison to narrative text genre, and participants tend to use more nominal expressions than pronominal ones.

\section{Conclusion}

The present study was aimed at examining the effect of text genre variability on the identification and the choice of various appropriate anaphoric expressions. Two pieces of English texts, including an expository text and a narrative one, were sent for all the participants through email message. The participants were provided ample time to study the texts carefully, identify the ellipted referents and choose appropriate anaphoric expressions.

The results of qualitative analysis of both narrative and expository text genres indicated that: a) in some environments identification is difficult regardless of short referential distance (cf. expository slots 7, 9, 31, 32 \& 33; narrative slots $34 \& 35$ ); b) there may be NP slots in which the majority of subjects identify the referent differently from the writer (cf. expository slots $31 \& 32$; narrative slots $20 \& 21$ ); c) the presence of grammatical constraint dictates full NP selection conformity (cf. expository slots 12,14, \& 18; narrative slot 10); d) recency of prior mention strongly determines the selectional performance (cf. expository slots $34 \& 35$; narrative slot 3,4, $5,6, \& 35)$; e) NP slot may contain referents whose mentions are purely optional (cf. expository slots $7 \& 8$ ); f) a long referential distance, between five to 20 clauses intervening between the two subsequent mentions of a given referent, may not impact on the difficulty of identification of referent (cf. expository slots $25,26 \& 27$; narrative slot 31$) ; g$ ) there is no identical pattern of reference in all cases of NP selection.

In all, concerning the identification of referents, the results revealed a significant difference between English expository and English narrative text genres $(\mathrm{p}=.003<0.05)$, though the difference between means were not high. With regards to the choice of anaphoric expressions, the results suggested significant difference between narrative and expository texts in terms of choice of NP of $(\mathrm{p}=.003<0.05)$ and PRN $(\mathrm{p}=.000<0.05)$. 
This study like other studies might have many inherent limitations. The major drawback of the study is the small size of the sample with 35 female advanced EFL learners, which may not have been a true representative of the larger population of Iranian EFL learners. Furthermore, the data was obtained from only one expository and one narrative text genres; thus not allowing for a more exhaustive generalization about the effect of text genre variability in identification of referents and choice of referring expressions. Given the fact that the study examined only advanced students, the results may not be true about other levels of language proficiency. Therefore, more studies can be conducted to make out whether the findings of the study are true with more of expository and narrative texts, across different levels of language proficiency including larger sample of the participants from different educational settings.

\section{References}

Allan, K. (1986). Linguistic meaning. London and New York: Routledge \& Kegan Paul.

Allan, K. (1987). Hierarchies and the choice of left conjuncts. Journal of Linguistics, 23, 51-77. http://dx.doi.org/10.1017/S0022226700011038

Ariel, M. (1990). Accessing noun-phrase antecedents. London: Routledge.

Arnold, J. E., \& Tanenhaus, M. K. (2007). Disfluency effects in comprehension: How new information can become accessible. In E. Gibson., \& N. Perlmutter (Eds.), The processing and acquisition of reference. Cambridge, MA: MIT Press.

Brewer, W. F. (1980). Literary theory, rhetoric, and stylistics: Implications for psychology. In R. J. Shapiro, B. C. Bruce, \& W. F. Brewer (Eds.), Theoretical issues in reading comprehension (pp. 221-239). Hillsdale, NJ: Erlbaum.

Bruner, J. S. (1986). Actual minds, possible worlds. Cambridge: Mass. London Harvard University Press.

Cain, K. (1996). Story knowledge and comprehension skill. In C. Cornaldi \& J. Oakhill (Eds.), Reading comprehension difficulties: Processes and intervention (pp. 167-192). Mahwah, NJ: Erlbaum.

Chafe, W. (1976). Givenness, contrastiveness, definiteness, subjects, topics, and point of view. In Charles N. Li (Ed.), Subject and topic (pp. 25-55). New York: Academic Press.

Chafe, W. (1994). Discourse, consciousness, and time. Chicago: University of Chicago Press.

Cote, N. C., Goldman, S. R., \& Saul, E. U. (1998). Students making sense of informational text: Relations between processing and representation. Discourse Processes, 25, 1-53. http://dx.doi.org/10.1080/01638539809545019

Eslami Rasekh, A. (1997). An investigation into discourse anaphoric relations: On the role of contextual information in anaphor resolution. Ph. D dissertation, Australia, University of Monash.

Fox, B. A. (1987). Discourse structure and anaphora: Written and conversational English. Cambridge: Cambridge University Press. http://dx.doi.org/10.1017/CBO9780511627767

Fukumura, K., \&. van Gompel, R.P.G. (2009). Speakers use their own, privileged discourse model to determine referents' accessibility during the production of referring expressions. In K. van Deemter, A. Gatt, R. van Gompel \& E. Krahmer (Eds.), Proceeding of workshop on the production of referring expressions: bridging the gap between computational and empirical approaches to reference. CogSci Society, Amsterdam, Netherlands.

Givón, T. (1983). Topic continuity in discourse: An introduction. In T. Givón (Ed.), Topic continuity in discourse: A quantitative cross-language study. Amsterdam: Benjamins.

Givón, T. (1985). Iconicity, isomorphism and non-arbitrary coding in syntax. In: John Haiman (Ed.), Iconicity in syntax (pp. 187-219). Amsterdam: Benjamins.

Givón, T. (1989). Mind, code, context: essays in pragmatics. Hillsdale, New Jersey: Lawrence Erlbaum Associates.

Givón, T. (1990). Syntax: A functional-typological introduction. Amsterdam: Benjamins.

Gundel, J., Hedberg, N., \& Zacharski, R. (1993). Cognitive status and the form of referring expressions in discourse. Language, 69, 274-307. http://dx.doi.org/10.2307/416535

Hempelmann, C. F., Dufty, D., McCarthy, P. M., Graesser, A.C., Cai, Z., \& McNamara, D.S. (2005). Using LSA 
to automatically identify givenness and newness of noun phrases in written discourse. In B. Bara (Ed.), Proceedings of the $27^{\text {th }}$ Annual Meetings of the Cognitive Science Society. (pp. 941-946). Mahwah, NJ: Erlbaum.

Huang, Y. (2000). Anaphora: A cross-linguistic approach. New York: oxford University Press.

Huang, Y. (2000). Discourse anaphora: Four theoretical models. Journal of Pragmatics, 32, 151-176. http://dx.doi.org/10.1016/S0378-2166(99)00041-7

Laury, R. (2001). Definiteness. In J. Verschueren, J. Olasstman, J. Blommaert \& C. Bulcaen (Eds.), Handbook of Pragmatics. Amsterdam: John Benjamins.

McNamara, D.S., Graesser, A.C., \& Louwerse, M.M. (in press). Sources of text difficulty: Across the ages and genres. In J.P. Sabatini \& E. Albro (Eds.) Assessing reading in the 21 st century: Aligning and applying advances in the reading and measurement sciences. Lanham, MD: R\&L Education.

Mitkov, R. (2002) Anaphor resolution. California: California University Press.

Nelson, K. (1996). Language in cognitive development: The emergence of the mediated mind. Cambridge, UK: Cambridge University Press. http://dx.doi.org/10.1017/CBO9781139174619

Prince, E. F. (1981). Toward a taxonomy of given-new information. In P. Cole (Ed.), Radical pragmatics. (pp. 223-256). New York: Academic Press.

Rubin, D.C. (1995). Memory in oral traditions: The cognitive psychology of epic ballads and counting-out rhymes. New York: Oxford University Press.

Tomlin, R. S. (1987). Linguistic reflections of cognitive events. In: R. S. Tomlin (Ed.), Coherence and grounding in discourse. (pp. 455-480). Amsterdam: Benjamins.

Tomlin, R. S., \& Pu, M. M. (1991). The management of reference in Mandarin discourse. Cognitive Linguistics, 2, 65-95. http://dx.doi.org/10.1515/cogl.1991.2.1.65

Tonjes, M.J., Ray, W., \& Zintz, M.V. (1999). Integrated content literacy. New York: The McGraw-Hill Publishers.

Williams, J. P., Hall, K. M., \& Lauer, K. D. (2004). Teaching expository text structure to young at-risk learners: Building the basics of comprehension instruction. Exceptionality, 12, 129-144.

http://dx.doi.org/10.1207/s15327035ex1203_2 


\section{APPENDIX}

\section{Appendix 1}

\section{English Expository Cloze Test}

Attorney General Eric Holder on Thursday defended the prosecution of terrorism suspects in civilian court after the top-ranking Senate Republican urged him to send two Iraqis to Guantanamo Bay rather than try them in Kentucky.

(1.) criticized what he called a "rigid ideology" among political opponents working to prevent terror trials that have been successfully handled by (2.) hundreds of times.

"Politics has no place in the impartial administration of justice," (3.) said in remarks to the American Constitution Society's convention.

Although (4.) didn't mention Senate Majority Leader Mitch McConnell by name, (5.) comments come two days after (6.) took to the Senate floor and urged (7.) Justice Department to send (8.) Waad Ramadan Alwan and Mohanad Shareef Hammadi to Navy-run prison at Guantanamo Bay. (9.) said a trial planned in his home could risk retaliatory attacks against judges, jurors and the broader community.

The Justice Department says there have been more than 400 convictions of terrorism-related charges in (10.).

"Not one of these individuals has escaped custody," (11.) said. And "not one of these (12.) arrested has been tried by a military commission."

Members of Congress have successfully fought (13.) over the prosecution of five other (14.) planned for New York City, including alleged Sept. 11. The Obama administration backed off the plan, saying it would instead prosecute them before a (15.).

(16.) issued a statement in response to (17.) speech that said foreign (18.) belong at the secure detention facility at Guantanamo Bay.

"There is wide, bipartisan opposition to giving the rights of U.S. citizens to men who tried to kill our troops on the battlefield," (19.) said.

(20.) insisted in (21.) speech that (22.) are "our most effective terror-fighting weapon."

"Despite this reality, we continue to see overheated rhetoric that is detached from history" (23.) said. "We see crucial national security tools, being put at risk by those who disparage the American criminal justice system and misguidedly claim that (24. ) cannot be tried safely in our (25.)".

(26.) and (27.) were arrested in the United States after being admitted as refugees from Iraq in 2009. Homeland Security officials have said (28.) slipped through cracks in the system that have since been fixed.

(29.) are charged in a 23-count indictment with conspiring to send weapons and money to al-Qaida in Iraq. (30.) waived their rights to remain silent and appear quickly before a judge.

Authorities say (31.) and (32.) from (33.) didn't make it to Iraq because of a tightly controlled investigation. The FBI said Alwan spoke of setting roadside bombs near Bayji, Iraq. (34.) said investigators found (35.) fingerprints on an unexploded bomb. 


\section{Appendix 2}

\section{English Narrative Cloze Test}

It began with a phone call. Not trusting his own telephone, Jeremie Dogan drove to a pay phone at a gas station to make the call. At the other end, Sam Cayhall listened to instructions he was given. Two days later, Cayhall left his home town of Clanton at dusk and drove to Greenville, Mississippi.

There (1.) drove slowly through the center of the city, and found offices of the Jewish lawyer Martin B. Kramer. It had been easy for the Klan to pick (2.) as their next target. (3.) had a long story of support for the civil rights. (4.) led protests against whites-only facilities. (5.) accused officials of racism. (6.) welcomed Negroes to his home.

The operation involved only three people. Mississippi Klan leader Dogan provided the money and enjoyed his role as organizer. The second man was (7.), one of the two men chosen By (8.) to do the actual dirty work. (9.) Family's connections with the (10.) went back very many years, but there was little Klan activity in Clanton so (11.) was considered harmless by the FBI. (12.) was a good choice.

At eleven, (13.) drove to Cleveland, where he looked for a green Pontiac. (14.) found the vehicle parked at a truck stop, got in, and drove (15.) out into open farming country. There (16.) stopped and opened the trunk. In box covered with newspapers, he found everything he needed. Then (17.) drove back into town and waited at an all-night café.

At 2 a.m., the third person in the team walked into the café and sat across from (18.) This young man's name was Rollie Wedge. His father was in the construction industry and had taught (19.) how to use explosives. (20.) knew little about (21.), but (22.) had done this kind of job several times. (23.) drank coffee together for an hour.

(24.) climbed into the green Pontiac and, with (25.) at the wheel. (26.) drove up to (27.) Office. (28.) parked the car in an alley behind (29.) office. (30.) quickly opened the trunk, removed (31.) and moved silently along to the door at the back of the office. Cayhall broke open the door and in seconds (32.) were both inside. In the main hallway there was a closet filled with old legal files.

(33.) quickly set the box on the floor in(34.), and wired the dynamite. It was a delicate exercise and Sam's heart raced as he waited. (35.) kept his back to the explosives, just in case something went wrong. They were in the office less than five minutes. 
Eslami, R. A., Tavakoli, M., Ghadiri, M., \& Zabihi, R. 